\title{
Targeted screening for primary immunodeficiency disorders in the neonatal period and early infancy
}

\author{
Nermeen Galal ${ }^{1}$, Mabroka Ohida ${ }^{2}$, Safa $_{\text {Meshaal }}^{3}$, Dalia Abd Elaziz ${ }^{1}$, Ismail Elhawary ${ }^{1}$
}

1. Department of Pediatrics, Faculty of Medicine, Cairo University, Cairo, Egypt.

2. Department of Pediatrics, Faculty of Medicine, Cairo University, Egypt- Libyan Arab Republic.

3. Department of Clinical and Chemical Pathology, Faculty of Medicine, Cairo University, Cairo, Egypt.

\begin{abstract}
:
Background: Primary immunodeficiency diseases (PID) comprise a group of more than 300 diseases that affect development and /or function of the immune system.

Objectives: The aim of this study was diagnosis of PID among a suspected group of neonates and infants within the first six months of life as well as identifying the warning signs of PID characteristic to this period.

Method: Fifty neonates presenting with warning signs of PID were enrolled in the study.

Results: The study revealed that twenty six patients (52\%) were diagnosed with Primary Immunodeficiency, $\mathrm{T}$ cell/combined immunodeficiency were noted as the most common PID class $(88.5 \%)$ with fourteen T-B-SCID patients $(70 \%)$ and six T-B+ SCID patients $(30 \%)$, phagocytic disorders were estimated to be $7.7 \%$ while $3.8 \%$ were unclassified immunodeficiency. The mean age of presentation for PID group was $1.42 \pm 1.38$ months with a diagnostic lag of $3.08 \pm 1.78$ months. Consanguinity was positive in $76.9 \%$ of the PID group. Lower respiratory tract infections, persistent fungal infections and lymphopenia were the most significant warning signs for diagnosing PID with a $\mathrm{p}$ value of (0.01). Combined, lower respiratory tract infections, fungal infections and lymphopenia were 12.3 times more likely to be associated with PID.
\end{abstract}

Conclusion: Focused screening in high risk neonates proved to be a valuable tool for diagnosis of PID disorders.

Keywords: Primary immunodeficiency disorders, neonatal period, early infancy.

DOI: https://dx.doi.org/10.4314/ahs.v19i1.18

Cite as: Galal N, Obida M, Meshaal S, Abd Elaziz D, I E. Targeted screening for primary immunodeficiency disorders in the neonatal period and early infancy. Afri Health Sci. 2019;19(1). 1449-1459. bttps:// dx.doi. org/10.4314/abs.v19i1.18

\section{Introduction}

Primary immunodeficiency diseases (PID) comprise a group of more than 300 distinct diseases arising from different genetic abnormalities that affect development and/or function of the immune system ${ }^{1}$. The exact prevalence of PID is uncertain because of lack of screening in newborns, national registries or reporting by government health surveys in many countries ${ }^{2}$; however PID prevalence of approximately 1:10.000 was reported in Australian, North American and European populations ${ }^{3}$. It is anticipated that high rates of consanguinity and inbreeding will lead to a higher incidence of autosomal recessive disorders ${ }^{4,5}$, however there is paucity of data on

\section{Corresponding author: \\ Nermeen Galal, \\ Department of Pediatrics, \\ Faculty of Medicine, Cairo University, Cairo, Egypt. \\ Email: nermeengalal@gmail.com}

prevalence of PID in developing countries and the Middle East region. Pilot studies reported the presence of autosomal recessive disorders in abundance and emphasized the late diagnosis ${ }^{5}$, Previous studies in Egypt have estimated a presentation in the first year of life among $29.7 \%$ of total cases diagnosed with PID ${ }^{4}$.

The PID clinical symptoms have a wide range of presentations that could be challenging during practice. The most commonly known PID disorder presenting in the neonatal period is Severe Combined Immunodeficiency (SCID); these patients usually present within the $1^{\text {st }}$ six months of life with failure to thrive, chronic diarrhea persistent oral thrush, skin rash, pneumonia, sepsis, disseminated BCG infection ${ }^{6}$. Other PID disorders may equally present in the neonatal period but are unrecognized due to lack of awareness e.g. Di-George syndrome, hyper $\mathrm{IgE}$ syndrome ${ }^{1}$. Diseases of immune dysregulation eg, Familial hemophagocytic lymphohistocytosis (FHL) and
African Health Sciences
(C) 2019 Galal et al. Licensee African Health Sciences. This is an Open Access article distributed under the terms of the Creative commons Attribution License (https://creativecommons.org/licenses/BY/4.0), which permits unrestricted use, distribution, and reproduction in any medium, provided the original work is properly cited. 
Immune Dysregulation Polyendocrinopathy Enteropathy $\mathrm{X}$-Linked (IPEX) also commonly present before the age of 6 months ${ }^{7}$.

The study aimed at diagnosis of PID among a suspected group of neonates and infants within the first six months of life as well as identifying the warning signs of PID characteristic to the neonatal period and early infancy.

\section{Methodology}

The study was conducted at Cairo University Specialized Pediatric Hospital, a tertiary referral center specialized in Primary Immunodeficiency Disorders. Informed consent was obtained from patients' guardians and Institutional review board approval waa obtained. The study included fifty cases recruited over a period of one year (from June 2015 through June 2016) of neonates and infants presenting with clinical manifestations suggestive of primary immunodeficiency diseases(PID) within the first six months of life.

Patients with the following features suggestive of PID were included:

- Recurrent /Persistent infections: unresolving pneumonia, recurrent pneumonia, sepsis, systemic candidiasis, deep seated abscesses that necessitate drainage.

- Patients presenting with other features suggestive of SCID (profound failure to thrive, persistent diarrhea, absent thymus).

- Patients with signs of Immune dysregulation (early inflammatory bowel disease, early onset of diabetes mellitus, autoimmune disorders as hepatitis, failure to thrive).

- Male patients with eczema and persistent thrombocytopenia associated with infections suggestive of Wiskott Aldrich syndrome.

- Previously affected or possibly affected siblings with PID.

- Previous unexplained sibling deaths at young age.

- Persistent Lymphopenia with unexplained cause: absolute lymphocyte count $<3000 / \mathrm{mm}^{3}$ in blood film.

- Patients with persistent neutropenia with unexplained cause: the absolute neutrophil count $<1500 / \mathrm{mm}^{3}$.

- Patients with delayed separation of the umbilical stump (more than one month) / high leukocyte count (>30,000/ $\mathrm{mm}^{3}$ ) suggestive of Leukocyte adhesion defect.

Cases with Infections explained by other causes e.g.( secondary to congenital heart disease without associated immunodeficiency, neurological disorders) and or failure to thrive due to other disorders were excluded from the study.

The patients were subjected to detailed history taking and examination. Laboratory investigations included complete differential blood counts, Peripheral blood lymphocytes were evaluated and surface-stained with anti-CD3 as pan-T marker, anti-CD4 for $\mathrm{T}$ helper lymphocytes, anti-CD8 for cytotoxic T cells, anti-CD19 or anti-CD20 as pan B markers, anti-CD16, and anti-CD56 for Natural killer cells by flow cytometry. Specific memory/naïve markers as CD45RA, CD45RO were used for determination of memory versus naïve $\mathrm{T}$ cells and $\operatorname{IgM} \operatorname{IgD}$ CD27 for B cells maturation when indicated. Serum immunoglobulin levels were determined by nephelometry. Neutrophils function was assessed by Dihydrorhodamine test when Chronic granulomatous disease was suspected. Some of the patients once diagnosed with PID underwent more extensive testing like molecular testing as Whole exome sequencing when possible.

\section{Statistical methods}

Categorical variables presented by number and presented. They were assessed by chi-square or Fischer exact test when appropriate. Odds ratio were calculated with 95\% confidence interval continuous variables presented by mean and standard deviation) SD). They were compared by t-student test. In all tests, $\mathrm{p}$ values were considered significant if less than 0.05 .

\section{Results}

The study population included twenty three females $(46 \%)$ and twenty seven (54\%) males. Thirty three (66\%) infants were born to consanguineous parents while seventeen (34\%) were born to non-consanguineous parents. Regarding the presenting warning signs indicating screening in the studied group collectively $(n=50)$; need for intravenous antibiotics to clear infections was found in thirty eight patients $(76 \%)$, thirty four patients $(68 \%)$ suffered from persistent or recurrent lower respiratory tract infections (pneumoniae) and persistent fungal infections in the form of oral and/or diaper moniliasis were found in twenty four patients (48\%). Ten patients $(20 \%)$ had history of previously affected family members \{ two families were consanguineous and eight families were non consanguineous)\}. Recurrent/deep skin or organ abscesses 
were found in $10(20 \%)$ patients. 9 patients $(18 \%)$ had serious infections, 9 patients $(18 \%)$ were suffering from failure to thrive, recurrent otitis media was present in 6 patients $(12 \%)$ and 2 patients $(4 \%)$ were on prolonged courses of antibiotics (more than two months) with little effect.

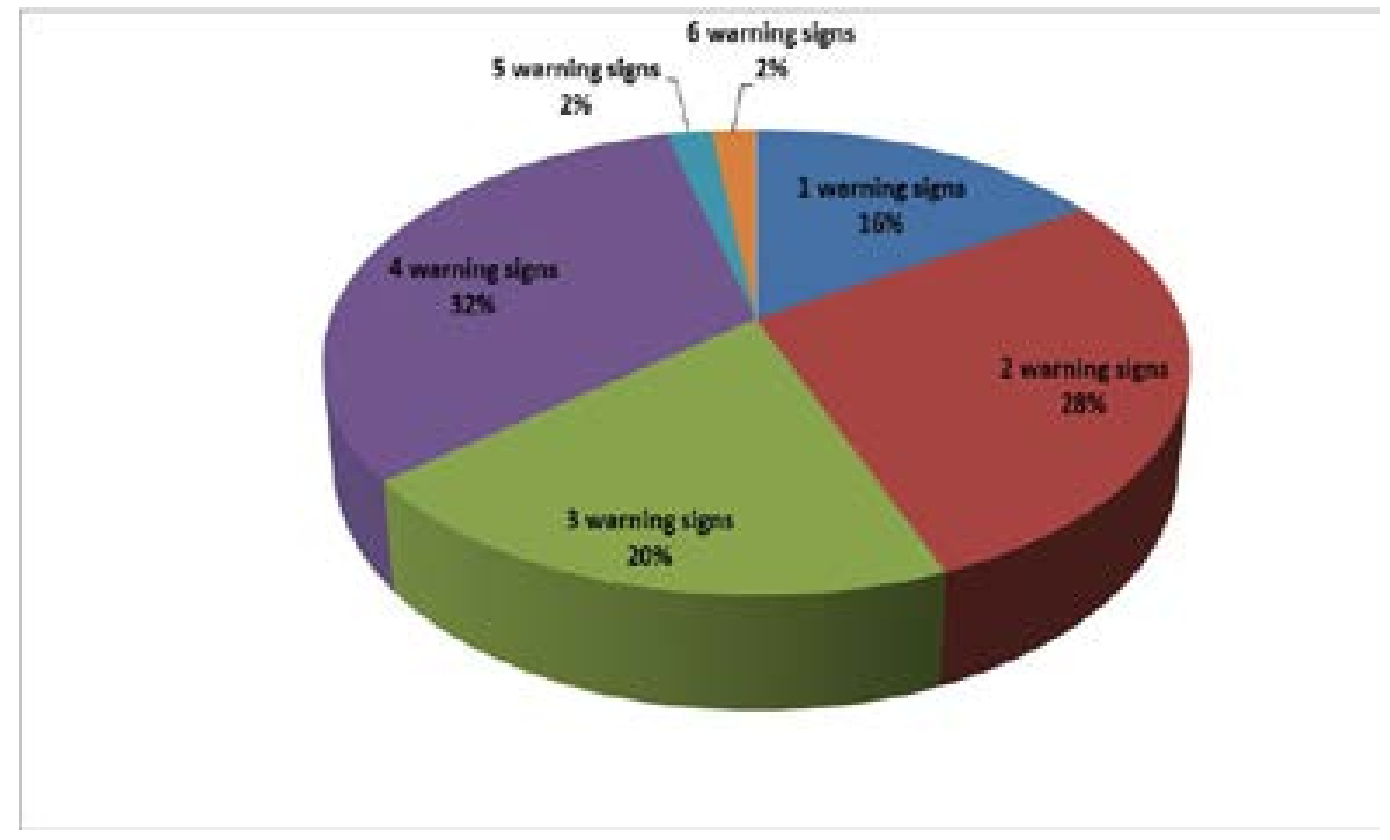

Figure(1): Percentage and Number of warning signs among the study population

1 patient had 6 warning signs, 1 patient had 5 warning signs, and 16 patients had 4 warning signs while 10 patients had 3 warning signs. 14 patients had 2 warning signs, and 8 patients had 1 warning sign (they were screened based on positive family history of PID).

The study population was screened and divided into two groups: Primary Immunodeficiency Disorders (PID) group which included 26 patients and Non-Immunodeficiency Disorders (Non PID) group including 24 patients. There was no statistical difference between PID and Non PID groups regarding age of presentation while there was a significant statistical difference in the age of diagnosis between both groups with a later age at diagnosis for PID group (P value 0.04). The mean age of first presentation in the PID group was (1.42 months, SD \pm 1.38$)$ whereas the mean age of diagnosis was (4.50 months, SD $\pm 1.81)$ with a diagnostic lag of (3.08months, $S D \pm 1.78)$ in the PID group.

Regarding the comparison of the warning signs between PID and non PID groups, lower respiratory tract infections and persistent fungal infections both were signifi- cant warning signs regarding PID patients with a $\mathrm{P}$ value of $(<0.01)$. Lower respiratory tract infections had a sensitivity of $85 \%$, a specificity of $50 \%$ while persistent fungal infections had a sensitivity of $69 \%$, a specificity of $75 \%$. Lymphopenia had a sensitivity of $69 \%$ and a specificity of $83 \%$, it was also a significant marker on comparing PID and Non PID groups with a p value of $<0.01$. Lower respiratory tract infections increased the chances of being diagnosed with PID 5.5 more times than patients with no history of lower respiratory tract infections while fungal infections increased the risk of being diagnosed as PID patient 6.8 more times than patients with no fungal infections .Lymphopenia was 15 times more likely associated with having PID whereas patients with combined lymphopenia, fungal infection and lower respiratory tract infections were 12.3 times more likely to be diagnosed with a PID disorder .

The Primary Immunodeficiency group included $26 \mathrm{pa}-$ tients. 23 patients were diagnosed with Combined Immunodeficiency Disorders; 20 cases were diagnosed as Severe Combined Immunodeficiency Disorders (SCID), including 2 cases as Omenn Syndrome, 1 patient was di- 
agnosed as Hyper Immunoglobulin E syndrome (HIES), one patient was diagnosed as Major histocompatibility complex (MHC) class II deficiency and 1 patient was diagnosed as isolated CD4 lymphopenia.

2 patients were diagnosed as phagocytic defects. 1 patient was diagnosed as Leukocyte Adhesion Deficiency (LAD) while the other 1 was diagnosed with Chronic Granulomatous Disease (CGD). 1 patient was categorized as unclassified Primary Immunodeficiency (suspected to be Mendelian Susceptibility to Mycobacterial disease-MSMD). Severe combined immunodeficiency group was further classified according to B cell counts into T-B-SCID and
T-B + SCID. T-B- SCID constituted 70\% ( $\mathrm{n}=14)$ of patients and $\mathrm{T}-\mathrm{B}+$ made up the remaining 30\% $(\mathrm{n}=6)$. Out of the 20 SCID cases, 10 were tested for the genetic mutations and diagnoses included; 3 cases of Janus $\mathrm{Ki}$ nase 3 (JAK3) Deficiency,2 cases of Adenosine Deaminase(ADA) deficiency, 2 cases of Recombinase Activating Gene(RAG) mutations and a single case of Artemis (DCLREIC),IL7R and IL2RG mutations .

The non-PID group included 9 patients with CMV infection, 4 with cow's milk allergy, 3 with malnutrition (improved with rehabilitation), 2 with Cystic Fibrosis, 1 with metabolic error. 5 had no pathological diagnosis to explain symptoms and only suffered those infections.

Table 1. Clinical characteristics of PID group

\begin{tabular}{|c|c|c|c|c|c|}
\hline No & Sex & $\begin{array}{l}\text { Age of diagnosis } \\
\text { (month) }\end{array}$ & $\begin{array}{c}\text { Age of onset of } 1^{\text {st }} \text { symptoms } \\
\text { (month) }\end{array}$ & Clinical manifestations & Diagnosis \\
\hline 1 & $\mathrm{M}$ & 1.3 & 1.3 & Pneumonia, fungal infections, sibling death. & SCID (ADA) \\
\hline 2 & $\mathrm{~F}$ & 0.5 & 0.5 & Previous affected sibling. & SCID (JAK3) \\
\hline 3 & $\mathrm{M}$ & 6 & 0.3 & Pneumonia, fungal infections. & SCID (IL7R) \\
\hline 4 & $\mathrm{~F}$ & 0.3 & 0.3 & Previous affected sibling, sibling death. & SCID(DCLRE1C) \\
\hline 5 & $\mathrm{~F}$ & 6 & 0.6 & Failure to thrive, otitis media, fungal infection. & SCID(JAK3) \\
\hline 6 & $\mathrm{M}$ & 6 & 3 & Pneumonia, evidence of fungal infection, otitis media, family death due to infection. & SCID(IL2RG) \\
\hline 7 & $\mathrm{~F}$ & 5 & 0.2 & Pneumonia, fungal infection, sibling death. & SCID (Unident) \\
\hline 8 & $\mathrm{M}$ & 3 & 0.2 & Pneumonia, fungal infection, sibling death, family death. & SCID (RAG1) \\
\hline 9 & M & 6 & 5 & $\begin{array}{l}\text { previous affected sibling, Pneumonia, fungal infection, family death, axillary lymphadenopathy } \\
\text { after BCG vaccine, sibling death. }\end{array}$ & SCID(RAG2) \\
\hline 10 & $\mathrm{M}$ & 2 & 0.2 & Pneumonia, sepsis, Pericardial effusion, family death. & SCID (ADA) \\
\hline 11 & $\mathrm{~F}$ & 3 & 0.5 & Failure to thrive, Pneumonia, family death, sibling death. & SCID(Unident) \\
\hline 12 & $\mathrm{M}$ & 6 & 1 & Pneumonia, fungal infection, organomegaly, sibling death. & SCID(Unident) \\
\hline 13 & $\mathrm{~F}$ & 3 & 2 & Pneumonia, fungal infection, deep seated abscesses. & SCID(Unidenti) \\
\hline 14 & $\mathrm{~F}$ & 6 & 2 & Failure to thrive, Pneumonia, fungal infection. sibling death. & SCID(Unident) \\
\hline 15 & $\mathrm{~F}$ & 6 & 4 & Failure to thrive, Pneumonia, evidence of fungal infection, recurrent of admission & SCID (JAK3) \\
\hline 16 & $\mathrm{~F}$ & 5 & 3 & Pneumonia, fungal infection, organomegaly, sibling death. & SCID(Unident) \\
\hline 17 & $\mathrm{M}$ & 5 & 0.3 & Pneumonia, fungal infection, deep seated abscesses, otitis media, sepsis, organomegaly, & SCID(Unident) \\
\hline 18 & $\mathrm{M}$ & 5 & 0.3 & Pneumonia, fungal infection, deep seated abscesses . & SCID(Unident) \\
\hline 19 & $\mathrm{~F}$ & 6 & 2 & Pneumonia, fungal infection, skin rash, siblingdeath. & Omenn syndrome \\
\hline 20 & $\mathrm{~F}$ & 4 & 2 & Pneumonia, fungal infection, Exfoliative skin rash. & Omenn syndrome \\
\hline 21 & $\mathrm{~F}$ & 6 & 4 & Failure to thrive, CNS infection, pneumonia, diarrhea and paralysis after Polio vaccine & $\begin{array}{l}\text { MHC class II } \\
\text { (RFXANK) }\end{array}$ \\
\hline 22 & M & 6 & 1.3 & Pneumonia, fungal infection, deep seated abscesses, meningitis, sepsis, family death. & $\begin{array}{l}\text { Isolated CD4 } \\
\text { lymphopenia }\end{array}$ \\
\hline 23 & $\mathrm{M}$ & 5 & 1 & Pneumonia, fungal infection, otitis media. & Hyper IgE \\
\hline 24 & $\mathrm{M}$ & 5 & 1.5 & Recurrent deep seated abscesses. & CGD \\
\hline 25 & M & 5 & 0.3 & $\begin{array}{l}\text { Ulcers, delayed umbilical stump separation, severe omphalitis, Pneumonia, otitis media, } \\
\text { organomegaly }\end{array}$ & LAD \\
\hline 26 & M & 5 & 0.2 & Lymphadenitis, Pneumonia, organomegaly, BCGoma, history of death in family with TB. & $\begin{array}{l}\text { Unclassified PID } \\
\text { (suspected } \\
\text { Mendelian } \\
\text { susceptibility to } \\
\text { mycobacterial } \\
\text { disease). }\end{array}$ \\
\hline
\end{tabular}

SCID: Severe Combined Immunodeficiency Disorders.

HIES: Hyper Immunoglobulin E syndrome.

MHC class II: Major histocompatibility complex class II deficiency.

LAD: Leukocyte Adhesion Deficiency.

CGD: Chronic Granulomatous Disease.

CNS: Central nervous system. 
Regarding the immunization history: 2 of the PID patients were not vaccinated and 24 were vaccinated with both polio and BCG vaccines prior to diagnosis. 1 patient developed diarrhea and acute flaccid paralysis (case No 21) following polio vaccination. First stool sample analysis revealed excretion of Sabin like SL3 which might have evolved later into Immunodeficiency-related vaccine-derived poliovirus (iVDPV) case, yet she passed away soon thereafter. Another patient developed BCGoma (case No 26) and 1 patient developed left axillary lymphadenopathy resolving spontaneously, results were statistically insignificant .
On comparing the Complete blood counts for both groups results showed a significant statistical difference with a $\mathrm{p}$ value of (0.001) for lymphopenia and absolute neutrophil count with a $\mathrm{p}$ value of $(0.004)$, neutropenia was found in 14 patients $(28 \%)$ of the studied group, 8 of them were PID and 6 were Non PID .The while White blood cells, platelet count, percentage of (Monocyte, Basophil, Eosinophil) showed no statistical significant values across the groups.

Table (2) Comparison between Primary Immunodeficiency Disorders group versus non primary immunodeficiency groups regarding complete blood picture:

\begin{tabular}{|l|l|l|l|l|l|}
\hline Lab results & \multicolumn{2}{l|}{ PID } & \multicolumn{2}{l|}{ Non PID } & \\
& Mean & SD \pm & Mean & SD \pm & P -value \\
\hline PLT & 370923.08 & 226433.73 & 370666.67 & 245018.66 & 0.997 \\
\hline WBCs & 9.32 & 10.61 & 12.93 & 8.08 & 0.185 \\
\hline Neutrophil \% & 0.50 & 0.19 & 0.33 & 0.20 & $0.004^{*}$ \\
\hline $\begin{array}{l}\text { Absolute neutrophil } \\
\text { count }\end{array}$ & 5593.84 & 7564.78 & 4220.57 & 3630.19 & 0.422 \\
\hline Lymph \% & 0.32 & 0.17 & 0.55 & 0.19 & $0.000^{*}$ \\
\hline $\begin{array}{l}\text { Absolute lymph } \\
\text { count }\end{array}$ & 2731.72 & 2768.07 & 5631.48 & 3243.44 & $0.001^{*}$ \\
\hline Monocyte \% & 0.11 & 0.07 & 0.11 & 0.16 & 0.924 \\
\hline Basophil \% & 0.01 & 0.01 & 0.00 & 0.00 & 0.064 \\
\hline Eosinophil \% & 0.04 & 0.09 & 0.02 & 0.03 & 0.360 \\
\hline
\end{tabular}

PID: Primary Immunodeficiency Disorders.

Non PID: Non Primary Immunodeficiency Disorders.

SD: standard deviation. 


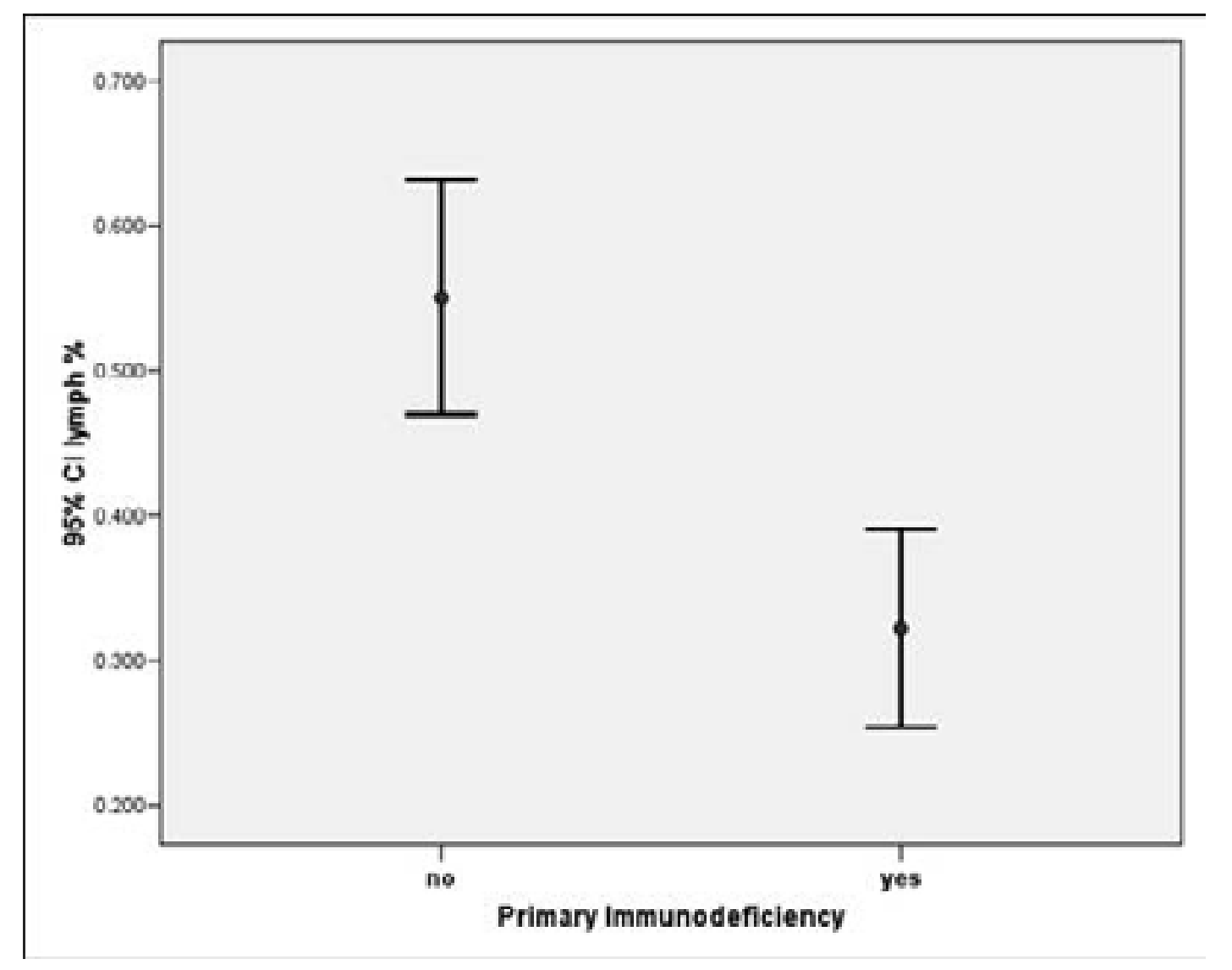

Figure (2 ): Comparison between Primary Immunodeficiency Disorders group versus non primary immunodeficiency groups regarding lymphocyte percentage.

On comparing the $\mathrm{CD}$ counts between both groups regarding the mean and $\mathrm{SD} \pm$ of values of $\mathrm{CD} 3, \mathrm{CD} 4$, CD8, CD19, CD56 absolute number and percentage (reflective of $\mathrm{T}$ cell function) results showed significant statistical difference between the two groups in the percentage and the absolute numbers of (CD3, CD4, CD8, CD19, CD56) with a $\mathrm{p}$ value of $(<0.01)$.

As for the outcome of the studied group; Eleven of the Primary immunodeficiency patients died (42.3\%), nine patient were still alive and symptomatizing (34.6\%), one received bone marrow transplantation and is alive and well, while six patients were lost to follow up $(23 \%)$.

\section{Discussion}

PIDs can be inherited in different patterns; the autosomal recessive (AR) pattern is the most common form of inheritance in patients born to consanguineous parents ${ }^{1}$. A previous study over a five year period from a tertiary PID referral center in Egypt demonstrated clearly that in highly consanguineous populations, autosomal recessive forms of PID disorders prevail and may also have peculiar characteristics pertaining to presentations and underlying genetic mutations ${ }^{8}$.

In our cohort consanguinity was highly positive among PID patients, a finding reported by other Middle Eastern countries, including Qatar, Iran, Kuwait, and other North African countries ${ }^{5,9}$.

Males were affected more than females, a trend seen in other parts of the world, including Europe and India ${ }^{10},{ }^{11}$. The ages reported in the present study were earlier than the previously estimated ${ }^{12}$, in Zagazig who reported that the median onset age of symptoms was 7 months (range, 1-84 months) and the median age at diagnosis was 24 months (3-120 months). Zeng et al. ${ }^{13}$ in their study from South China reported a median age at diagnosis of 10 months range (2-159 months). Hadizadehet al. ${ }^{14}$ based on twelve studies, again reported a higher age at diagnosis of PID patients which ranged from 12.0 to 74.5 months. The relative younger age of presentation and di- 
agnosis reported hereby may be attributed to the focused screening of neonates, the high number of SCID patients among our cohort and or increased awareness as some cases had previous affected family members.

The lag in diagnosis in the present study $(3.08 \pm 1.78$ months) was similar to a pervious study conducted in Ain Shams University ${ }^{9}$ who reported a diagnostic lag of 3 months while it was less than what was reported in other countries like Tunisia (18 months), Morocco (24 months) and France $(1 \text { year })^{15,16,17}$.

Patients were assessed for warning signs of PID according to the criteria established by the Jeffrey Modell Foundation. However, the warning signs carry limitations as a screening tool because they may fail to identify some patients with serious PIDs, as recently reported ${ }^{18,19}$. Because other clinical symptoms can raise the suspicion of PID, in Sweden, Gruber et al has extended the inclusion criteria beyond the 10 warning signs to incorporate additional symptoms including recurrent fever or fever with duration of more than 6 weeks, and an excessive number of upper respiratory tract infections $\left(>8\right.$ per year) ${ }^{20}$. In a study done by Brodszk et al. ${ }^{21}$, recurrent otitis media was the most common warning sign of PID and therefore the inclusion criteria were expanded .

Respiratory symptoms represent an important marker pointing the attention toward PIDs ${ }^{22}$. In our study, lower respiratory tract infections were the most significant warning sign for diagnosing PID as it was reported in $22 / 26$ patients. Lower respiratory infections had a sensitivity of $85 \%$ and a specificity of $50 \%$. Consistent with our finding, eighty nine patients were studied in Argentina and the main clinical manifestation among patients with PID was respiratory tract infections ${ }^{23}$, and also in Korea where the most common first manifestation in PID patients was pneumonia ${ }^{24}$.

Tenacious fungal infections are commonly reported in the context of acquired conditions (HIV infection, immunosuppressive therapies, prolonged antibiotic therapies, diabetes mellitus) or various Primary Immunodeficiency Disorders as with severe combined immunodeficiencies (SCID) and with combined immunodeficiencies (CID) ${ }^{25}$. In our study persistent fungal infections in the form of tenacious oral and/or diaper moniliasis were found in twenty four patients $(48 \%)$ and it was a significant warning sign regarding PID patients with a sensitivity of $69 \%$ and a specificity of $75 \%$.
The warning sign of having a family member with a known immunodeficiency is advocated as one of the three most important signs for identifying patients with PID $^{19}$. However, in our study group, a positive family history was reported only in 3/26 patients with PID.

In our study the need for intravenous antibiotics to clear infections was observed in 22 out of 26 PID patients while failure to thrive was reported in 6 patients. Similar to our findings, need for intravenous antibiotics to clear infections has been identified as one of three key warning signs for PID in South Africa ${ }^{26}$ while in a study done in Guanajuato, Mexico by Guerra et al. ${ }^{27}$, which included 26 PID cases, need for intravenous antibiotics was the most frequent warning sign $(19 / 26=73.08 \%)$ followed by two or more pneumonias within 1 year $(14 / 26=53.85 \%)$, and failure of an infant to gain weight or grow normally $(12 / 26=46.15 \%)$.

In Egypt, a study by Reda et al. ${ }^{9}$ of the most frequent warning sign among patients with PID ,the need for intravenous antibiotics came first. Failure to thrive was more frequent in the categories of combined $\mathrm{T}$ - and B-cell immunodeficiencies and predominantly antibody deficiency. Recurrent deep-skin and organ abscesses and deep-seated infections were significantly more frequent in the category of congenital defects in phagocyte number, function, or both. In Zagazig, Egypt another study done by $\mathrm{A}$ Hussien et $\mathrm{al}^{12}$, over a period of two years including 50 patients found pneumoniae, bronchitis and otitis media were the most common presentations in PID patients .Recurrent severe infections as pneumonia, chronic diarrhea, and failure to thrive are commonly thought of as classic symptoms of PID and patients with combined lower respiratory tract infections, fungal infections and lymphopenia were 12.3 times more likely to be diagnosed with a PID disorder.

Primary Immunodeficienies were reported in $52 \%$ of the study group; $T$ cell/combined immunodeficiencies were noted as the most common PID class $(88.5 \%)$ with fourteen T_B_SCID patients $(70 \%)$ and six T-B + SCID patients $(30 \%)$. In a previous study in Egypt, combined immunodeficiency disorders (CID) constituted around 30\% of all the categories reported while CID with syndromic disorders represented around $46.8 \%$. Studies from other Arab countries showed similar results. In Tunisia, the percent of CID was $28.5 \%$ among other PIDs diagnosed while in Saudi Arabia, the percentage was higher (59.7 $\%)^{5}, 28,29,8$. 
Other countries reported a high prevalence of combined disorders however it was not the most common category as in Kuwait, where CID represented 21\%, following the antibody defects. In Oman, phagocytic disorders were reported as the most common PID category ${ }^{30,31}$. In Iran; predominantly antibody deficiencies were the most common subcategory of PID (32.3\%) followed by combined immunodeficiencies $(22.3 \%)^{32}$.

The present study revealed that SCID constituted the major category of PID disorders among our studied patients. A previous study from the largest PID referral center in Egypt documented a high incidence of SCID with a relatively late age at diagnosis and a diagnostic lag of several months, among the 140 cases diagnosed with severe combined immunodeficiency (SCID)/Omenn syndrome, $(50.5 \%)$ cases were diagnosed with T-B-SCID, $(38.5 \%)$ with T-B + SCID, and 10 were diagnosed with Omenn syndrome $(11 \%)^{8}$. A study comparing SCID patients diagnosed in Kuwait and USA revealed a different age of onset and different molecular causes, which highlights the importance of newborn screening ${ }^{33}$.

Regarding North Africa, Morocco, as well as Tunisia, data showed that among T-B + SCIDs, only a minority had $\mathrm{X}$-linked form, while autosomal recessive forms as interleukin 7 receptor alpha chain (IL7R $\alpha$ ) expression defect and janus kinase 3 (Jak-3) deficiencies were observed in more patients ((Barbouche et al., 2011). RAG mutations were confirmed to be not uncommon in the Egyptian SCID population as previously reported by Meshaal et al. (2015).Immunophenotyping of 30 SCID in Morocco patients showed a predominance of $\mathrm{T}-\mathrm{B}-\mathrm{SCID}$ (63.3\%), with T-B-NK+ being the most common subtype (46.7 $\%)^{35}$.

Obligatory Immunization Program in Egypt includes oral polio vaccine (OPV) and BCG vaccine at birth.Left axillary lymphadenopathy, BCGoma, diarrhea and acute Flaccid Paralysis were complications observed in some cases of PID patients in our study after live attenuated vaccinations. These vaccines may be lethal and cause severe/disseminated disease in patients with immunodeficiency patients ${ }^{36}$. Wild poliovirus type- 2 has been eradicated and use of live type- 2 vaccine has been terminated globally, all type- 2 polioviruses are under strict laboratory containment protocols. Re-emergence may arise from prolonged asymptomatic excretion of poliovirus by primary immune deficient (PID) patients ${ }^{37}$. Patients with primary immune deficiency disorders (PIDD) who receive oral poliovirus vaccine (OPV) may transmit immunodeficiency associated vaccine-derived polioviruses (iVDPVs) and cause paralytic Polio ${ }^{38}$. For this reason, oral polio vaccine (OPV) and BCG vaccination must be avoided in all the severe forms of PID $^{39,40,41}$. In families with suspicious family history, vaccines should be with held till screening occurs.

As patients with PID suffer from recurrent infections definite treatment with bone marrow transplantation or gene therapy is warranted but unfortunately is limited by availability of matched donor and the cost of this therapy. In our study one SCID patient was transplanted, discharged and completely cured.

In order to enhance the overall understanding of PID for the community and clinicians, it is not only necessary to recognize and diagnose the disease early, but also to improve the level of treatment. Diagnosing the patients early gives them a better chance and a better quality of life before they succumb to infections. It also provides precious time for matching and administrative processes needed for treatment in a resource limited country.

\section{Conflict of interest}

We declare that there is no conflict of interest.

\section{References}

1. AL-Herz W, Bousfiha A, Casanova JL, Chapel H, Conley ME, Cunningham-Rundles C, Etzioni A, Fischer A, Franco JL, Geha RS, Hammarström L, Nonoyama S, Notarangelo LD, Ochs HD, Puck JM, Roifman CM, Seger R, Tang ML. Primary immunodeficiency disease: an update the classification from the international union of immunological societies expert committee for primary immunodeficiency. Front Immunol. 2011;2:54.

2. Verbsky JW, Grossman WJ: Cellular and genetic basis of primary immune deficiencies. Pediatr Cli North Am. 2006;53(4):649-84.

3. Eades-Perner AM, Gathmann B, Knerr V, Guzman D, Veit D, Kindle G, Grimbacher B; ESID Registry Working Party.The European internet-based patient and research database for primary immunodeficiencies: results 200406.Clin Exp Immunol. 2007 Feb;147(2):306-12. 
4. Reda SM, Afifi HM, Amine MM.Primary immunodeficiency diseases in Egyptian children: a single-center study. J Clin Immunol. 2009 May;29(3):343-51. doi: 10.1007/ s10875-008-9260-x.

5. Barbouche MR, Galal N, Ben-Mustapha I, Jeddane L, Mellouli F, Ailal F, Bejaoui M, Boutros J, Marsafy A, Bousfiha AA. Primary immunodeficiencies in highly consanguineous North African populations. Ann N Y Acad Sci. 2011;1238:42-52 PubMed.

6. Modell V, Megan K, Modell F: An analysis and decision tool to measure cost benefit of newborn screening for severe combined immunodeficiency (SCID)and related T-cell lymphopenia. Immunol Res, 2014 ;60(1):145-52. PubMed.

7. Gambineri and Torgerson: Genetic disorders with immune dysregulation. Cell Mol Life Sci. 2012; 69:49-58. PubMed.

8- Galal N, Meshaal S, Elhawary R, ElAziz DA, Alkady R, Lotfy S, Eldash A, Boutros J, Elmarsafy A. Patterns of Primary Immunodeficiency Disorders Among a Highly Consanguineous Population: Cairo University Pediatric Hospital's 5-Year Experience. J Clin Immunol. 2016;36(7):649-55. PubMed.

9. Reda SM, El-Ghoneimy DH, Afifi HM. Clinical Predictors of Primary Immunodeficiency Diseases in Children.2013. Allergy Asthma Immunol Res. 2013;5(2):88-95

10. Gathmann B, Binder N, Ehl S, Kindle G. The European internet-based patient and research database for primary immunodeficiencies: update 2011. Clin Exp Immunol. 2012;167(3):479-91.

11. Chinnabhandar V, Yadav SP, Kaul D, Verma IC, Sachdeva A. Primary immunedeficiency disorders in the developing world: data from ahospital based registry in India. Pediatr Hematol Oncol. 2014;31(3):207-11

12. Hussien AS, Abd El Salam M, Mohammad M, Zidan A. Assessment of Primary Immunodeficiency disordres amoung children At Zagazig University hospital Z.U.M.J. Vol.20; N.2; March; 2014

13. Zeng H, Tao Y, Chen X, Zeng P, Wang B, Wei R, Yao C, Xie Y, Li F, Tang Y, Cui Y, Sun G. Primary immunodeficiency in south China: clinical features and a genetic subanalysis of 138 children. J Investig Allergol Clin Immunol. 2013;23(5):302-8

14. Hadizadeh H, Salehi M, Khoramnejad S, Vosoughi K, Rezaei N. The association between parental consanguinity and primary immunodeficiency diseases: A systematic review and meta-analysis Pediatr Allergy Immunol. Pediatr Allergy Immunol. 2017;28(3):280-287.

15. Bousfiha AA, Jeddane L, El Hafidi N, Benajiba N, Rada N, El Bakkouri J, et al. First report on the Moroccan registry of primary immunodeficiencies: 15 years of experience (1998-2012). J Clin Immunol. 2014;34(4):459-68 16. CEREDIH. The French national registry of primary immunodeficiency-diseases. Clin Immunol. 2010;135(2):264-72.

17. Garcia JM, Gamboa P, de la Calle A, Hernandez MD, Caballero MT, García BE, Labrador M, Lahoz C, Longo Areso N, Lopez Hoyos M, Martínez Quesada J, Mayorga L, Monteseirin FJ, Sanz ML. Diagnosis and management of immunodeficiencies in adults by allergologists. I Investig Allergol Clin Immunol. 2010;20(3):185-94.

18. Arkwright PD, Gennery AR: Ten warning signs of primary immunodeficiency: a new paradigm is needed for the 21st century. Ann N Y Acad Sci. 2011;1238:7-14. PubMed.

19. Subbarayan A, Colarusso G, Hughes SM, Gennery AR, Slatter M, Cant AJ, Arkwright PD: Clinical features that identify children with primaryimmunodeficiency diseases. Pediatrics. 2011;127(5):810-6. PubMed.

20. Gruber C, Keil T, Kulig M, Roll S, Wahn U, Wahn V. History of respiratory infections in the first $12 \mathrm{yr}$ among children from a birth cohort. Pediatr Allergy Immunol. 2008, 19(6):505-12.

21. Brodszki N, Jönsson G, Skattum L, Truedsson L. Primary immunodeficiency in infection-prone children in southern Sweden: occurrence, clinical characteristics and immunological findings. BMC Immunol. 2014;15:31

22. O'Sullivan MD, Cant AJ. The 10 Warning signs: a time for change? Curr Opin Allergy Clin Immunol. 2012;12:58894.

23. Lozano NA, Lozano A, Sasia LV, Saranz RJ, Agresta MF, del Pilar Bovina Martijena M,Ianiero L, Grenat AR. Clinical comparison between patients with selective immunoglobulin A deficiency and other primary immunodeficiencies. Arch Argent Pediatr. 2015;113(2):141-5. PubMed.

24. Rhim JW, Kim KH, Kim DS, Kim BS, Kim JS, Kim CH, Kim HM, Park HJ, Pai KS, Son BK, Shin KS, Oh MY, Woo YJ, Yoo Y, Lee KS, Lee KY, Lee CG, Lee JS, Chung EH, Choi EH, Hahn YS, Park HY, Kim JG. Prevalence of primary immunodeficiency in Korea. $J$ Korean Med Sci. 2012 ;27(7):788-93. PubMed. 
25. Lanternier F, Cypowyj S, Picard C, Bustamante J, Lortholary O, Casanova JL, Puel A. Primary immunodeficiencies underlying fungal infections. Curr Opin Pediatr. 2013;25(6):736-47.

26. Esser M. Primary immunodeficiency missed opportunities and treatment challenges: review article. Current Allergy \& Clinical Immunology, 2012; 25(4):184 - 188.

27. Guani-Guerra E, GarcIa-RamirezUN, Jimenez-Romero AI, Velazquez-Avalos JM, Gallardo-Martinez G, Mendoza-Espinoza FJ. Primary immunodeficiency diseases at reference and high-specialty hospitals in the state of Guanajuato, Mexico. Biomed Res Int. 2013;2013:187254.

28. Al-Saud B, Al-Mousa H, Al Gazlan S, Al-Ghonaium A, Arnaout R, Al-Seraihy A , Elshorbagi S, Elsayed N, Afzal J, Al-Dhekri H, Al-Muhsen S. Primary immunodeficiency diseases in Saudi Arabia: a tertiary care hospital experience over a period of three years (2010-2013). J Clin Immunol. 2015;35(7):651-60.

29. Mellouli F, Mustapha IB, Khaled MB, Besbes H, Ouederni M, Mekki N,. Ali MB, Larguèche B, Hachicha M, Sfar T, Gueddiche N, Barsaoui S, Sammoud A, Boussetta K, Becher SB, Meherzi A, Guandoura N, Boughammoura L, Harbi A, Amri F, Bayoudh F, Jaballah NB, Tebib N20, Bouaziz A, Mahfoudh A, Aloulou H, Mansour LB, Chabchoub I, Boussoffara R, Chemli J, Bouguila J, Hassayoun S, Hammami S, Habboul Z, Hamzaoui A, Ammar J, Barbouche MR, Bejaoui M. Report of the Tunisian Registry of Primary Immunodeficiencies: 25-Years of Experience (1988-2012). J Clin Immunol. 2015;35(8):745-53.

30. Al-Tamemi S, Elnour I, Dennison D. Primary immunodeficiency diseases in Oman: five years' experience at Sultan Qaboos University Hospital. World Allergy Organ J. 2012;5(5):52-6.

31. Al -Herz W. Primary immunodeficiency disorders in Kuwait: first report fromKuwait National Primary Immunodeficiency Registry. J Clin Immunol. 2008;28(2):186-93. 32. Aghamohammadi A, Mohammadinejad P, Abolhassani H, Mirminachi B, Movahedi M, Gharagozlou M, Parvaneh N, Zeiaee V, Mirsaeed-Ghazi B, Chavoushzadeh Z, Mahdaviani A, Mansouri M, Yousefzadegan S, Sharifi B, Zandieh F, Hedayat E, Nadjafi A, Sherkat R, Shakerian B, Sadeghi-Shabestari M, Hosseini RF, Jabbari-Azad F, Ahanchian H, Behmanesh F, Zandkarimi M, Shirkani A, Cheraghi T, Fayezi A, Mohammadzadeh I, Amin R, Aleyasin S, Moghtaderi M, GhaffariJ, Arshi S, Javahertrash N, Nabavi M, Bemanian MH, Shafiei A, Kalantari
N, Ahmadiafshar A, Khazaei HA, Atarod L, Rezaei N. Primary immunodeficiency disorders in Iran: update and new insights from the third report of the national registry. J Clin Immunol. 2014;34(4):478-90.

33. Al-Herz W, Notarangelo LD, Sadek A, Buckley R, USIDNET Consortium. Combined Immunodeficiency in the United States and Kuwait: comparison of patients'characteristics and molecular diagnosis. Clin Immunol. 2015;161(2):170-3.

34. Meshaal S., El Hawary R., Elsharkawy M., Mousa R., Farid R., Abd. Elaziz D, Alkady R, Galal N., Massaad M, Boutros J., El Marsafy A. Mutations in recombination activating gene 1 and 2 in patients with severe combined immunodeficiency disorders in Egypt. Clin Immunol. 2015; 158: 167-172. PubMed.

35. El-Maataoui O, Ailal F, Naamane H, Benhsaien I, Jeddane L, Farouqi B, Benslimane A, Jilali N, Oudghiri M, Bousfiha A. Immunophenotyping of severe combined immunodeficiency in Morocco. IBS J Sci. 2011;26: 161164. PubMed.

36. Shearer WT, Dunn E, Notarangelo LD, Dvorak CC, Puck JM, Logan BR, Griffith LM, Kohn DB, O'Reilly RJ, Fleisher TA, Pai SY, Martinez CA, Buckley RH, Cowan MJ. Establishing the diagnostic criteria for serve combined immunodeficiency disease (SCID), leaky SCID and Omenn syndrome: the Primary Immune Deficiency Treatment Consortium experience. J Allergy Clin Immunol. 2014; 133(4):1092-98.

37. Weil M, Shulman LM, Heiman S, Stauber T, Alfandari J, Weiss L, Silberstein I, Indenbaum V, Mendelson E, Sofer D. Prolonged excretion of type 2 poliovirus from a primary immune deficient patient during the transition to a type-2 poliovirus-free world, Israel, 2016. Euro Surveill. 2016;21(47).

38. Hossain M. S. Sazzad, Jeanette J. Rainey, Anna-Lea Kahn, Ondrej Mach, Jayantha B. L. Liyanage, Ahmed Nawsher Alam, Choudhury A. Kawser, Asgar Hossain, Roland Sutter, and Stephen P. Luby. Screening for Longterm Poliovirus Excretion Among Children With Primary Immunodeficiency Disorders: Preparation for thePolio Posteradication Era in Bangladesh. J Infect Dis. 2014;210 Suppl 1:S373-9.

39. Walkovich K, Connelly JA. Primary immunodeficiency in the neonate: Early diagnosis and management. Semin Fetal Neonatal Med. 2016;21(1):35-43.

40. Rubin LG, Levin MJ,Ljungman P, Davies EG, Avery 
R, Tomblyn M, Bousvaros A, Dhanireddy S, Sung L, Keyserling H, Kang I. Infectious Diseases Society of America.. 2013 IDSA clinical practice guideline for vaccination of the immunocompromised host. Clin. Infect. Clin Infect Dis. 2014;58(3):309-18.
41. DeVries AS, Harper J, Murray A, Lexau C, Bahta L, Christensen J, Cebelinski E, Fuller S, Kline S, Wallace GS, Shaw JH, Burns CC, Lynfield R. Vaccine-derived poliomyelitis 12 years after infection in Minnesota. N. Engl. J. Med. 2011;364(24), 2316-23. 